\title{
Ketamine-Induced Changes in the Signal and Noise of Rule Representation in Working Memory by Lateral Prefrontal Neurons
}

\author{
닐a Ma, ${ }^{1}$ Kevin Skoblenick, ${ }^{2}$ Jeremy K. Seamans, ${ }^{5}$ and Stefan Everling ${ }^{1,2,3,4}$ \\ ${ }^{1}$ Department of Physiology and Pharmacology, ${ }^{2}$ Department of Anatomy and Cell Biology, ${ }^{3}$ Brain and Mind Institute, and ${ }^{4}$ Robarts Research Institute, \\ University of Western Ontario, London, Ontario, N6A 3K7 Canada, and ${ }^{5}$ Brain Research Centre and Department of Psychiatry, Faculty of Medicine, \\ University of British Columbia, Vancouver, British Columbia, V6T 2B5 Canada
}

Working memory dysfunction is an especially debilitating symptom in schizophrenia. The NMDA antagonist ketamine has been successfully used to model working memory deficits in both rodents and nonhuman primates, but how it affects the strength and the consistency of working memory representations remains unclear. Here we recorded single-neuron activity in the lateral prefrontal cortex of macaque monkeys before and after the administration of subanesthetic doses of ketamine in a rule-based working memory task. The rule was instructed with a color cue before each delay period and dictated the correct prosaccadic or antisaccadic response to a peripheral stimulus appearing after the delay. We found that acute ketamine injections both weakened the rule signal across all delay periods and amplified the trial-to-trial variance in neural activities (i.e., noise), both within individual neurons and at the ensemble level, resulting in impaired performance. In the minority of postinjection trials when the animals responded correctly, the preservation of the signal strength during the delay periods was predictive of their subsequent success. Our findings suggest that NMDA receptor function may be critical for establishing the optimal signal-to-noise ratio in information representation by ensembles of prefrontal cortex neurons.

Key words: ketamine; nonhuman primate; prefrontal cortex; rule; saccade; working memory

Significance Statement

In schizophrenia patients, working memory deficit is highly debilitating and currently without any efficacious treatment. An improved understanding of the pathophysiology of this symptom may provide critical information to treatment development. The NMDA antagonist ketamine, when injected at a subanesthetic dose, produces working memory deficit and other schizophrenialike symptoms in humans and other animals. Here we investigated the effects of ketamine on the representation of abstract rules by prefrontal neurons, while macaque monkeys held the rules in working memory before responding accordingly. We found that ketamine weakened the signal-to-noise ratio in rule representation by simultaneously weakening the signal and augmenting noise. Both processes may be relevant in an effective therapy for working memory impairment in schizophrenia.

\section{Introduction}

In patients with schizophrenia, cognitive symptoms such as working memory impairments are particularly debilitating and difficult to remediate (Elvevåg and Goldberg, 2000; GoldmanRakic et al., 2004; van Os and Kapur, 2009; Lett et al., 2014). To understand the neural processes underlying this deficit, the

\footnotetext{
Received May 12, 2015; revised June 26, 2015; accepted July 16, 2015.

Author contributions: S.E. designed research; K.S. performed research; L.M. and K.S. analyzed data; L.M., J.K.S., and S.E. wrote the paper.

This work was supported by grants from the Canadian Institutes of Health Research.

The authors declare no competing financial interests.

Correspondence should be addressed to Liya Ma at the above address. E-mail: liyamariama@gmail.com.

DOI:10.1523/JNEUROSCI.1839-15.2015

Copyright $\odot 2015$ the authors $\quad 0270-6474 / 15 / 3511612-11 \$ 15.00 / 0$
}

NMDA antagonist ketamine has been successfully used to model working memory dysfunction in both rodents (Wesierska et al., 1990; Enomoto and Floresco, 2009; Rushforth et al., 2011) and nonhuman primates (Condy et al., 2005; Skoblenick and Everling, 2012; Blackman et al., 2013; Gil-da-Costa et al., 2013).

Working memory, the process of actively holding and manipulating information in memory (Baddeley and Della Sala, 1996), was thought to rely on persistent activation of prefrontal cortex (PFC) neurons (Fuster and Alexander, 1971; Funahashi et al., 1989; Quintana and Fuster, 1999) or on linear ramping activity throughout the delay period (Quintana and Fuster, 1999; Durstewitz, 2004; Johnston and Everling, 2006). NMDA receptor currents are likely involved in these persistent firing modes, because their long decay time supports activity in the absence of contin- 
A

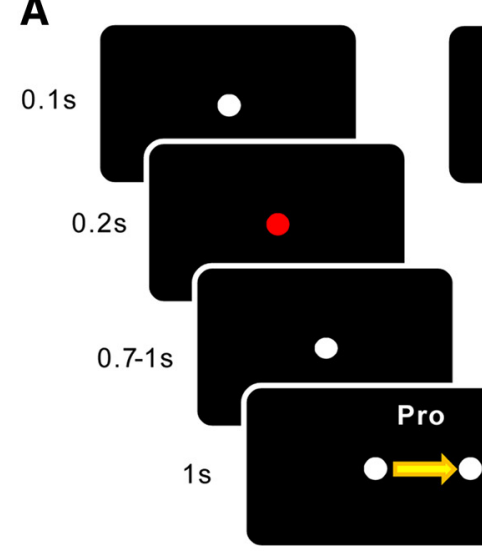

B

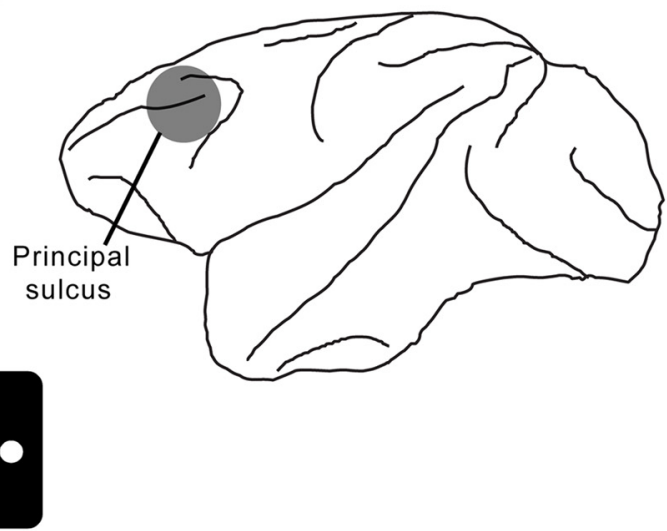

Figure 1. Schematic illustrations of methods and materials. $\boldsymbol{A}$, Experimental paradigm. Each trial started with a white fixation circle, which lasted for $0.1 \mathrm{~s}$ before turning green or red, signaling a prosaccade or antisaccade trial, respectively (the contingency was reversed for the other subject). In $0.2 \mathrm{~s}$, the central spot turned back to white, which initiated the delay period lasting anywhere from 0.7 to $1 \mathrm{~s}$ and ending upon the onset of the peripheral stimulus. According to the green/red instruction cue, the animals now made either a prosaccade or antisaccade with reference to the peripheral stimulus and were rewarded for correct responses. $\boldsymbol{B}$, Recording location. All electrodes were placed within the bilateral lateral prefrontal cortex. The locations were confirmed with MRI.

uous synaptic input (Spruston et al., 1995; Wang, 1999; Durstewitz et al., 2000a). Equally important are the inhibitory currents through $\mathrm{GABA}_{\mathrm{A}}$ channels, which help to counteract high-activity states and limit the representations currently active (Durstewitz et al., 2000a,b; Seamans et al., 2003). It is believed that the coordinated activity of glutamatergic pyramidal neurons and GABAergic interneurons shape the representations maintained during the delay periods (Wang, 1999; Rao et al., 2000; Constantinidis and Wang, 2004).

Ketamine-induced blockade of NMDA receptors on pyramidal neurons may reduce persistent activity and therefore the strength or fidelity of working memory representations. Alternatively, if NMDA antagonists exert a stronger effect on fast-spiking GABAergic interneurons (Moghaddam et al., 1997; Olney and Farber, 1997; Lorrain et al., 2003; Jackson et al., 2004; Homayoun and Moghaddam, 2007), the net effect could be disinhibition of pyramidal neurons (Jackson et al., 2004; Coyle, 2006; Skoblenick and Everling, 2012). Under disinhibition coupled with the reduction of NMDA currents on pyramidal neurons, persistent activities can only be supported by AMPA currents (Gutkin et al., 2001; Hansel and Mato, 2001; Koulakov, 2001; Latham and Nirenberg, 2004), which are transient and often nonspecific, and may lead to poor working memory performance (Skoblenick and Everling, 2012). Hence, it is unclear whether ketamine impairs working memory by weakening information representation, by augmenting the variance of the representation, or both.

Previous studies from our laboratory have demonstrated that ketamine severely impaired performance in a working memory task that required the animals to make prosaccades to or antisaccades away from the target, with the rule dictated by a color cue given before the delay (Skoblenick and Everling, 2012, 2014). Here we deconstruct the effects of ketamine on signal, noise, and the signal-to-noise ratio (SNR) of pyramidal neurons and ensembles during the delay period. Since the rules dictate the appropriate saccadic response during the postdelay stimulus, the "signal" was defined as the difference in the averaged delay-period activities between the prosaccade and antisaccade trials, whereas the "noise" was the trial-to-trial variance. We found that ketamine reduced the ensemble SNR by weakening the signal and amplifying the noise simultaneously, at both single-unit and ensemble levels.

\section{Materials and Methods}

Data were collected from two male adult rhesus monkeys (Macaca mulatta) following guidelines of the Canadian Council of Animal Care and protocols approved by the Animal Use Subcommittee of the Western University Council on Animal Care. All experimental procedures have been described in detail previously (Skoblenick and Everling, 2014).

Behavioral task. The task has been described in detail in previous manuscripts from our laboratory (Skoblenick and Everling 2012, 2014). On each trial, the instruction cue for the rule was presented following an initial $100 \mathrm{~ms}$ fixation period by changing the central white fixation spot to either red or green (Fig. 1A). For Monkey O, the green cue indicated that the animal had to look toward the subsequent peripheral stimulus (i.e., prosaccade), whereas the red cue indicated that a saccade away from the stimulus (i.e., antisaccade) was required (Fig. 1A). The color-rule mapping was reversed for Monkey T. The cue lasted for $200 \mathrm{~ms}$ and turned back to white for a variable delay of $700-1000 \mathrm{~ms}$, before the onset of the peripheral stimulus $8^{\circ}$ to either the left or right of the fixation spot. To obtain a water reward, the animal had to saccade to the correct target location within a circular window with a diameter of $8^{\circ}$ (Fig. $1 A$ ). Trials involving prosaccades to the left and the right and those involving antisaccades to the left and the right were pseudo-randomized. The animals' eye positions were recorded and digitized at $120 \mathrm{~Hz}$ using an ISCAN infrared pupillary tracking system (ISCAN).

Multielectrode recording. Extracellular recordings were conducted with a semichronic screw microdrive system (Neuronitek) attached to 32 individually moveable tungsten microelectrodes (FHC). The electrode distances were $1 \mathrm{~mm}$ center to center in a $6 \times 6$ grid with the four corner electrodes acting as reference electrodes. The positioning of the system was guided by anatomical MR images to target the area in and around the posterior principal sulcus (Fig. 1B). To ensure a relatively unbiased sampling of lateral PFC (LPFC) neural activity, we did not prescreen neurons for task-related responses. The microdrive system remained implanted for up to 2 weeks before it was removed for cleaning and maintenance. Neuronal data were acquired and filtered with a multiacquisition processor system (Plexon). Recorded neurons were sorted off-line using Offline Sorter (Plexon). Horizontal and vertical eye positions and the occurrence of behavioral events were also stored in the Plexon acquisition system.

Drug administration. Each experimental session began with a minimum 10 min period of preinjection activities during which the animal performed blocks of trials in a pseudo-randomized order. Then during a $\sim 15$ s pause to the experiment, the animals received a single subanesthetic intramuscular injection of either $0.4 \mathrm{ml}$ of ketamine $(0.4 \mathrm{mg} / \mathrm{kg}$, diluted in sterile saline) or $0.4 \mathrm{ml}$ of sterile saline into their right tricep brachii muscle. This dose of ketamine has been found to elicit cognitive deficits with minimal anesthetic effects in rhesus monkeys (Condy et al., 
2005; Stoet and Snyder, 2006; Shen et al., 2010; Blackman et al., 2013). Previous studies from our laboratory have compared the behavioral effects of ketamine with an injection of $0.4 \mathrm{ml}$ of sterile saline (Skoblenick and Everling, 2012, 2014); hence, the saline controls will not be analyzed here. The behavioral paradigm resumed after the injection and continued for at least $40 \mathrm{~min}$. Ketamine injections were spaced by at least $4 \mathrm{~d}$ to avoid cumulative dosing effect.

Data analysis. A total of nine ensembles $\left(N_{\min }=14\right)$ containing 307 neurons were recorded from two monkeys. All neurons were included in the analyses. One animal had a 15 min preinjection period on each recording session, whereas the other animal had $10 \mathrm{~min}$. After the injection, the behavioral effect of ketamine took $\sim 5 \mathrm{~min}$ to develop and almost returned to baseline by $25 \mathrm{~min}$ after injection. Therefore, for each session, 10 min immediately preceding the injection and the period from 5 to $25 \mathrm{~min}$ after injection were included in all analyses. All analyses focused on the delay period in each trial, starting at the disappearance of the instruction cue and ending after the onset of the peripheral stimulus. The analyses were performed using custom-made MATLAB (Mathworks) algorithms.

Standard deviation and coefficient of variation across trials. For all analyses, we first binned the activities of each neuron at $100 \mathrm{~ms}$ and calculated its firing rate in each bin. All analyses involve activities taken exclusively from the delay period. Because the delay period varied between 700 and $1000 \mathrm{~ms}$, six consecutive $100 \mathrm{~ms}$ bins of activities were used from each trial. The sixth bin was defined as the bin immediately preceding the one containing the onset of the peripheral stimulus. To quantify trial-to-trial variance, we averaged the firing rates across the six bins for each trial for each neuron. The binning procedure was used to stay consistent with later analyses where $z$-scores were used.

Neural activities throughout each session were divided into $10 \mathrm{~min}$ periods, with one preinjection period and four postinjection periods. Because the number of trials varied in each time period and because sample SD is affected by sample size, we randomly selected 11 trials for each rule and each treatment condition for the calculation of SD and coefficient of variation (CV). This process was repeated 1000 times, and the results were averaged. The coefficient of variation was calculated as the ratio between the $\mathrm{SD}$ in firing rate across trials and the mean firing rates across trials.

Single-unit analysis of SNR. The SNR was defined as the differences in delay-period firing rates between prosaccade and antisaccade trials, divided by the trial-to-trial variance (Eq. 1). We calculated the SNR separately for preinjection and postinjection periods. If the overall level of neural activity were held constant, the signal would simply be the difference between the mean activities associated with the two rules. Any possible differences in the overall level of activity (e.g., as a result of ketamine injection) were taken into account by subtracting the difference between two random trial sets within that condition from the actual firing rate differences associated with the two rules. The end result was the signal specific to rules. The noise, defined as trial-to-trial variance in delay-period firing rates, was computed as the pooled SD of both trial types: $\sqrt{\left(\sigma_{i, t \in P}^{2}+\sigma_{i, t \in A}^{2}\right) / 2}$.

Therefore, the equation for SNR for the task rule representation in single units can be written as follows:

SNR

$$
=\frac{\left|\left\langle\left\{r_{i}(t) \mid t \epsilon P\right\}\right\rangle-\left\langle\left\{r_{i}(t) \mid t \epsilon A\right\}\right\rangle\right|-\left|\left\langle\left\{r_{i}(t) \mid t \epsilon R_{1}\right\}\right\rangle-\left\langle\left\{r_{i}(t) \mid t \epsilon R_{2}\right\}\right\rangle\right|}{\sqrt{\left(\sigma_{i, t \in P}^{2}+\sigma_{i, t \epsilon A}^{2}\right) / 2}}
$$

where $r_{i}(t)$ denotes the firing rate of neuron $i$ in time period $t, \cdot \cdot$ denotes the mean, $\sigma^{2}$ denotes variance, $P$ is the prosaccade trial set, $A$ is the prosaccade trial set, $R_{1}$ is a random trial set containing both prosaccade and antisaccade trials, and $R_{2}$ is the random trial set containing all the remaining trials.

We used the bootstrapping procedure to control for the difference in trial number in different treatment conditions and different sessions. Specifically, for each neuron both before and after ketamine injection, 24 trials were randomly selected from the prosaccade and the antisaccade trials, respectively, to compute the single-neuron SNR. The selected trials were then shuffled to create the two random trial sets, which were used to control for the general activity-enhancing effect of ketamine. This process was repeated 100 times, and the results were averaged to produce the final SNR. In one analysis comparing correct and error trials (see Fig. $3 D$ ), nine correct and nine error trials were randomly selected in each iteration because of the limited numbers of correct and error trials. To illustrate its temporal changes, we also calculated the SNR for the $10 \mathrm{~min}$ period immediately before injection and four consecutive $10 \mathrm{~min}$ periods after the injection (see Fig. 4).

Ensemble analysis of SNR based on Mahalanobis distance. For SNR analyses at both single-unit and ensemble levels, we took the $z$-scores of the $100 \mathrm{~ms}$ binned data in an attempt to equalize the contributions from neurons with both high and low firing rates.

The firing rates of all neurons in a given ensemble (i.e., all simultaneously recorded neurons in a single session) can be plotted in a multiple single-unit activity (MSUA) space (Durstewitz et al., 2010; Hyman et al., 2012), where an $N \times 1$ population activity vector ( $N$ is ensemble size) gives rise to a single point in the $\mathrm{N}$-dimensional space. We defined ensemble SNR as the Mahalanobis distance $\left(D_{\text {Mah }}\right)$ between the clusters of points in the MSUA space representing delay-period activities from prosaccade trials and antisaccade trials. $D_{\mathrm{Mah}}$ is calculated as the Euclidean distance between the two groups of population vectors (i.e., clusters of points in the MSUA space), divided by their pooled covariance matrix. The Euclidean distance $\left(D_{\text {Euc }}\right)$ is computed between the trial-averaged ensemble activities associated with the two rules in the $\mathrm{N}$-dimensional space. By our definition, the $D_{\mathrm{Euc}}$ is the rule signal at the ensemble level. The denominator for the calculation of $D_{\mathrm{Mah}}$, the pooled covariance matrix, contains the trial-to-trial variance of each neuron as well as the covariance between each pair of neurons in the ensemble. It therefore is the ensemble-level equivalence to our definition of noise at the singleunit level. Because the covariance in the activities of any two neurons depends on both their correlation and the variance in each neuron, we computed the averaged pairwise correlation coefficient instead of the covariance in the ensembles. Since the $D_{\mathrm{Mah}}$ has $D_{\mathrm{Euc}}$ as the numerator and the pooled covariance matrix as the denominator, it is an ideal way of quantifying the ensemble signal-to-noise ratio.

Analogous to the single-unit analysis, we had to account for ketamineinduced changes in overall activity. To disentangle the general activityenhancing effect of ketamine from the specific changes in SNR for rule representation, we subtracted the $D_{\text {Euc }}$ between shuffled trial sets from the difference between the $D_{\text {Euc }}$ between rules to obtain the signal component of the SNR.

To control for differences in ensemble size and number of trials, a bootstrapping procedure was applied by randomly selecting 11 neurons and 24 trials. The computation was iterated 100 times for ensemble size and 100 times for trial number.

For visualization purposes, we used multidimensional scaling (MDS) to reduce the MSUA space of a single session to a two-dimensional plane (see Fig. $6 A, C$ ). It should be noted that all group statistics (shown in Fig. 5 ) were performed in $N$-dimensional space ( $N$ is bootstrapped ensemble size) rather than in any dimension-reduced space.

Waveform analysis for separation of broad-spiking and narrow-spiking neurons. We also tested whether ketamine had different effects on broadspiking neurons (BSNs; putative pyramidal neurons) and narrowspiking neurons (NSNs; putative fast-spiking interneurons). First, the waveform data were read into MATLAB from .nex files using codes provided by NeuroExplorer (Nex Technologies). We then computed the peak-to-trough latency of the recorded extracellular waveforms of each neuron. Based on the bimodal distribution of the peak-to-trough latencies of the neuronal population recorded in the current study, we defined neurons with peak-to-trough latencies shorter than $270 \mu$ s as NSNs and those with latencies longer than $270 \mu$ s as BSNs. This empirically determined criterion is also identical to that used in previous studies from our laboratory using the same techniques (Johnston et al., 2009; Skoblenick and Everling 2014). After the classification, we characterized the firing rates and the variance in the activities of both types of neurons, both before and after ketamine injection. We also applied the single-unit analysis of the SNR to each type of neuron separately. 
A

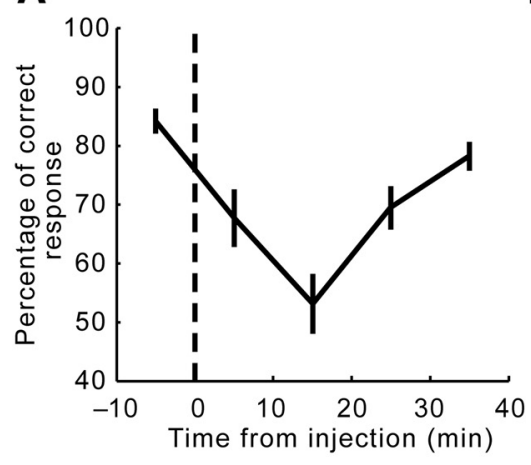

B

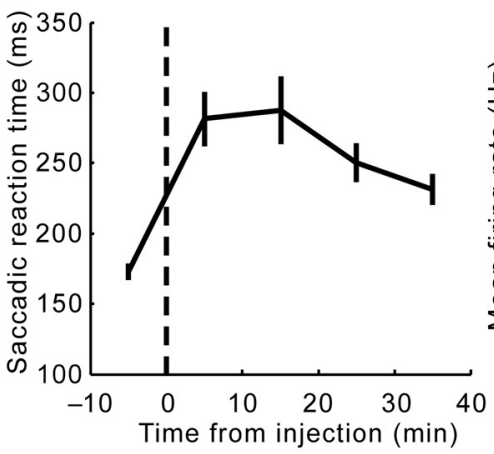

C

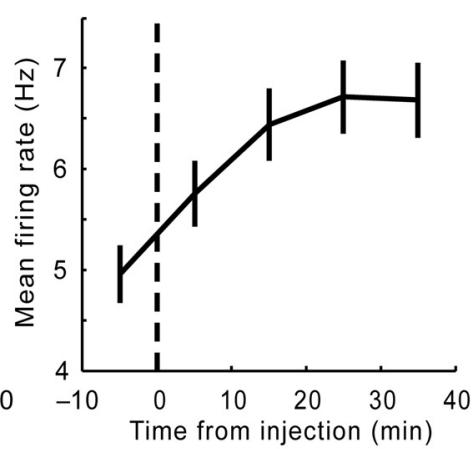

D

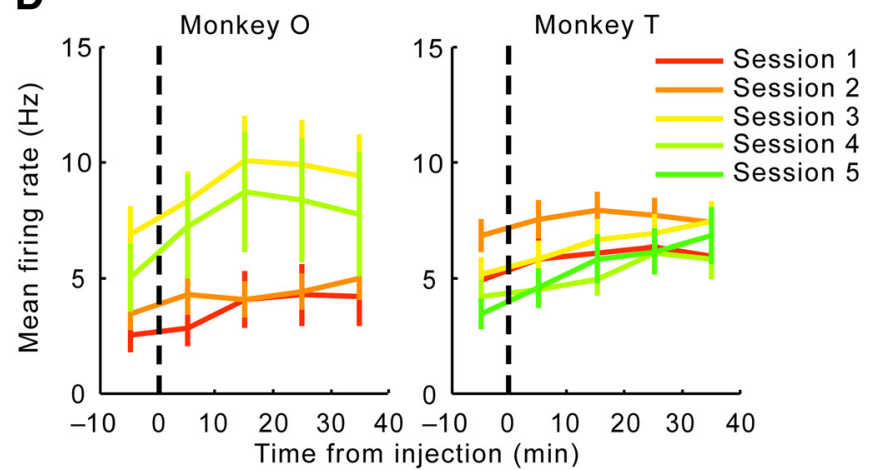

F

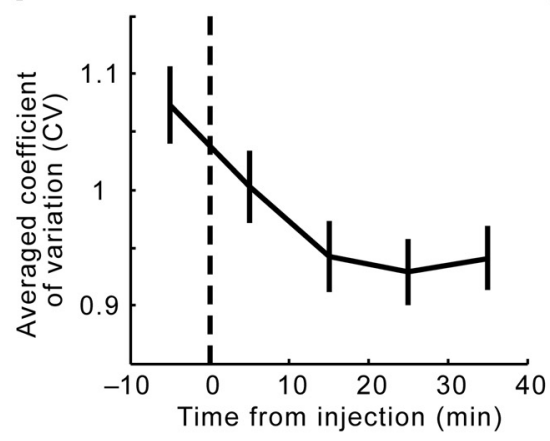

G

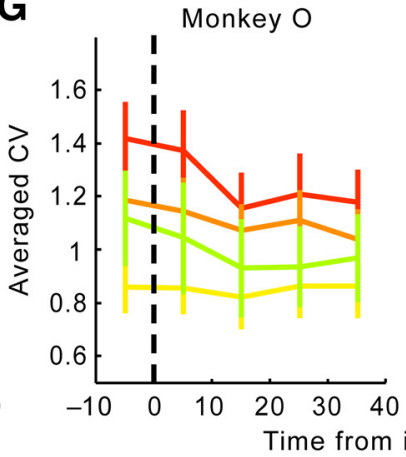

E

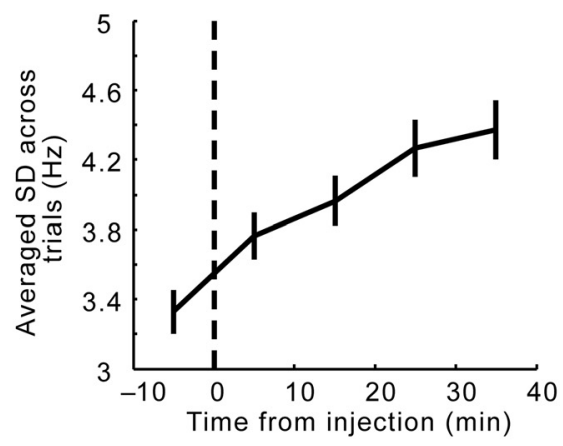

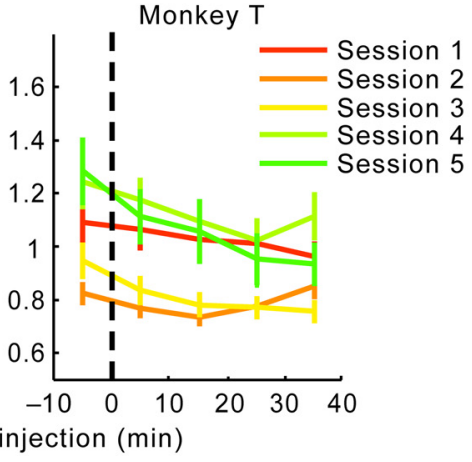

Figure 2. Changes in behavior and descriptive statistics of LPFC neural activity throughout the sessions. $A$, Ketamine reduced the percentage of correct trials, which reached the lowest point during the second $10 \mathrm{~min}$ period after injection, and gradually recovered. $\boldsymbol{B}$, Ketamine increased the averaged reaction time of the saccadic response, which plateaued during the first 20 min after injection, and then decreased but did not fully recover by the end of the sessions. C, The mean firing rates across all neurons recorded increased gradually after ketamine injection and eventually plateaued toward the end of the sessions. $\boldsymbol{D}$, Ketamine injection increased the mean firing rate across neurons recorded in every session from both Monkey 0 and Monkey $T$. Each session is plotted in a distinct color. $\boldsymbol{E}$, Ketamine injection increased the trial-to-trial SD across all neurons at a steady rate throughout the sessions. $\boldsymbol{F}$, The CV, or the SD-to-mean ratio in activities across all trials, decreased after ketamine injection during the first $20 \mathrm{~min}$ after injection and remained at the same level for the rest of the recording sessions. This indicates that the mean firing rate in $C$ increased at a greater pace than the SD shown in E. G, Ketamine injection increased the averaged $\mathrm{CV}$ across neurons recorded in every session from both Monkey 0 and Monkey $\mathrm{T}$. Error bars indicate the SEM.

\section{Results}

While past studies considered activity during all task epochs (Johnston and Everling, 2006; Johnston et al., 2009; Skoblenick and Everling, 2012), here we focused on prefrontal activity specifically during the delay periods. We included all neurons in the analysis, and not just those that exhibited specific activity patterns during delay periods, to avoid assumptions regarding to how a neuron may encode information.

\section{Effects of ketamine on behavior and LPFC activities during the delay periods}

Consistent with previous findings from our laboratory (Skoblenick and Everling, 2012, 2014), ketamine decreased the percentage of correct responses (repeated-measures ANOVA, $F_{(4,32)}$ $=11.7, p=5.9 \times 10^{-6}$; Fig. $2 A$ ) as well as increased the response reaction time in our working memory task (repeated-measures ANOVA, $F_{(4,32)}=14.1, p=9.9 \times 10^{-6}$; Fig. $\left.2 B\right)$. The first $10 \mathrm{~min}$ after the injection saw a significant decrease in performance (Tukey's post hoc test, $p=0.015$ ) and an increase in reaction time ( $p=0.00013)$. Performance deteriorated even more during the second $10 \mathrm{~min}$ postinjection period $(0-10$ vs $10-20 \mathrm{~min} ; p=$ $0.043)$, whereas reaction time stayed at the same level $(p=$ 0.997). Toward the end of the sessions, whereas the percentage of correct responses fully recovered (30-40 min vs preinjection period; $p=0.74)$, the reaction time remained longer than before the treatment $(p=0.016)$.

We then examined different aspects of prefrontal activity, including the mean firing rates, trial-to-trial SD in firing rates, and the CV during delay periods, to see if they responded to ketamine after a similar time course to either behavioral measurement. A 

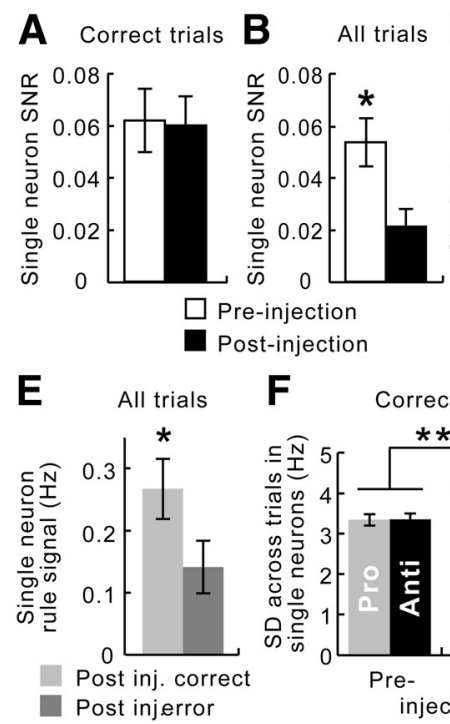

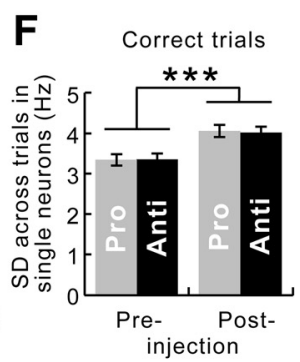

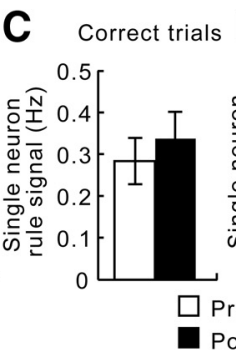

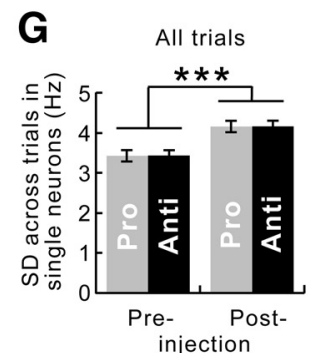

H Pre-injection

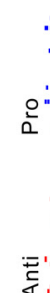

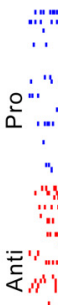

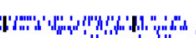
(1)

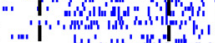
Ling
Post-injection

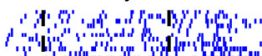

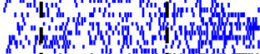

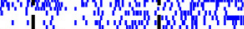
, I : iving ing

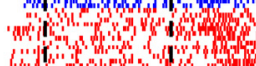

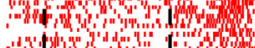
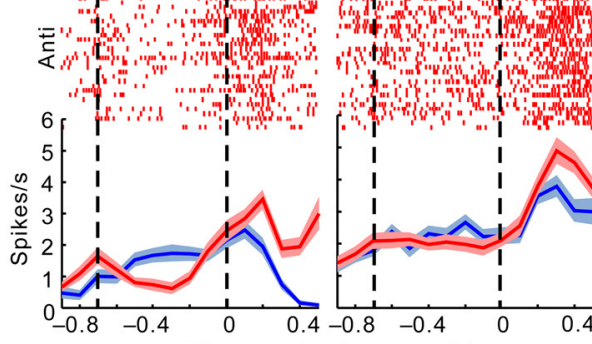

Figure 3. In individual neurons, ketamine weakened the SNR for task rules, attributable to both a reduction in the signal and an increase in the noise. $\boldsymbol{A}$, Considering correct trials only, the SNR was unchanged by acute ketamine administration (white bar, before injection; black bar, after injection). $\boldsymbol{B}$, When error trials were also included, the SNR was significantly weakened after the injections. $\boldsymbol{C}$, The rule signal, measured as the difference between the mean firing rates associated with prosaccade and anti-saccade trials, remained the same in correct trials after ketamine injections. $\boldsymbol{D}$, When error trials were also included, the rule signal dropped significantly after the injections. $\boldsymbol{E}$, After ketamine injections, the rule signal was significantly lower during the delay periods in error trials (dark gray) than in correct trials (light gray). $F$, Considering correct trials only, the noise, measured as the SD across all prosaccade (gray) or antisaccade (black) trials, increased as a result of ketamine. The amount increased was similar for both rules. $\mathbf{G}$, When error trials were also included, the SD across all prosaccade (gray) or antisaccade (black) trials also increased as a result of ketamine. The amount increased was similar for both rules. Error bars indicate the SEM. $\boldsymbol{H}$, Activity of a single neuron in both types of trials. In the raster plots, each line segment represents a single spike. Lines at the bottom depict the mean, and their shade reflects the SEM across all prosaccade (blue) and antisaccade (red) trials, respectively. The dashed lines delimit the delay periods. Whereas the neuron responded differently in the prosaccade (blue line) and the antisaccade (red line) trials before ketamine injection (left), this distinction mostly disappeared after the injection (right). The loss of the SNR for rules occurred despite the increase in overall activity. ${ }^{*} p<0.05,{ }^{* * *} p<0.0001$.

main effect of ketamine in past studies is that it increased overall firing (Moghaddam et al., 1997; Jackson et al., 2004). Consistent with these data, in the present study, ketamine injection also enhanced overall activity (repeated-measures ANOVA, $F_{(4,1224)}$ $=37.8, p<4.9 \times 10^{-324}$; Fig. $2 C$ ). This activity-enhancing effect was consistently observed across sessions within subjects as well as across subjects (Fig. 2D). Although the mean firing rates reached a plateau between 10 and 20 min after the injection (Tukey's test; before vs $0-10 \mathrm{~min}$ after injection, $p=4.3 \times 10^{-5}$; $10-20 \mathrm{~min}$ vs $20-30 \mathrm{~min}$ after injection, $p=0.52 ; 10-20 \mathrm{~min}$ vs $30-40$ min after injection, $p=0.64$ ), the SD across trials continued to rise toward the end of the sessions (repeated-measures ANOVA and Tukey's test, $F_{(4,1224)}=44.4, p<4.9 \times 10^{-324}$; before vs $0-10 \mathrm{~min}$ after injection, $p=2.6 \times 10^{-5} ; 10-20 \mathrm{~min}$ vs $20-30 \mathrm{~min}$ after injection, $p=0.0062 ; 10-20 \mathrm{~min}$ vs $30-40 \mathrm{~min}$ after injection, $p=5.7 \times 10^{-5}$; Fig. $2 E$ ). Because SD increased at a slower rate than the mean firing rate after ketamine injection, the $\mathrm{CV}$, or the SD-to-mean ratio, decreased as a result of the manipulation (repeated-measures ANOVA, effect of time, $F_{(4,1168)}=28.3, p<4.9 \times 10^{-324}$; Tukey's test, $p=5.3 \times 10^{-4}$, $1.7 \times 10^{-5}, 1.7 \times 10^{-5}$, and $1.7 \times 10^{-5}$, respectively, for the comparison between baseline and $0-10,10-20,20-30$, and $30-40$ min postinjection periods; Fig. $2 F$ ). Again, this reduction in $\mathrm{CV}$ was consistently observed across sessions within subjects and across subjects (Fig. 2G).

\section{Effects of ketamine on the SNR for rule representation in single neurons}

The SNR for task rules was defined as the difference between the delay-period activities associated with the two rules (adjusted for the general rise in activity), relative to the trial-to-trial variance in delay-period activity (Eq. 1). When only correct trials were considered, the SNR among single neurons did not change as a result of ketamine injection (paired $t$ test, $t_{(249)}=0.0195, p=0.98$; Fig. $3 A$ ). By contrast, when errors were included in the analysis, the SNR in single neurons decreased significantly after ketamine treatment (paired $t$ test: $t_{(304)}=2.97, p=0.0032$; Fig. $3 B$ ). Therefore, ketamine disrupted the representation of rule information within individual PFC neurons during the delay periods and especially on error trials.

To fully understand the change in SNR, we analyzed the signal and the noise separately. The rule signal, or the average background-corrected firing rate difference between prosaccade and antisaccade trials, was the same before as after ketamine when only correct trials were considered (paired $t$ test, $t_{(252)}=$ $-0.762, p=0.45$; Fig. $3 C$ ). In contrast, when error trials were included, the rule signal was significantly weakened by ketamine (paired $t$ test, $t_{(306)}=2.65, p=0.0084$; Fig. $3 D$ ). On error trials, the signal was already weaker during the delay periods immediately before the errors were made compared with the signal strength preceding correct responses (paired $t$ test, $t_{(252)}=2.05$, $p=0.041$; Fig. $3 E$ ). This was true regardless of whether the preceding trial contained an error or not.

The noise component of the SNR reflected the trial-to-trial variance and was operationalized as the SD in firing rates, pooled from both prosaccade and antisaccade trials. The variance in these two trial types is presented side by side in Figure $3 F$. The trial-to-trial variance during the delay periods was increased by ketamine even when only correct trials were considered (repeated-measures ANOVA, main effect of ketamine, $F_{(1,504)}=$ $79.4, p<4.9 \times 10^{-324}$; Fig. $\left.3 F\right)$. This was equally true for both prosaccade and antisaccade trials (no effect of rule: $F_{(1,504)}=$ $0.055, p=0.81$; Fig. $3 F$ ). As one would expect, the trial-to trial variance was still present after ketamine injection when error trials were also included (repeated-measures ANOVA, main effect of ketamine, $F_{(1,612)}=123.4, p<4.9 \times 10^{-324}$; Fig. $\left.3 G\right)$. 
A

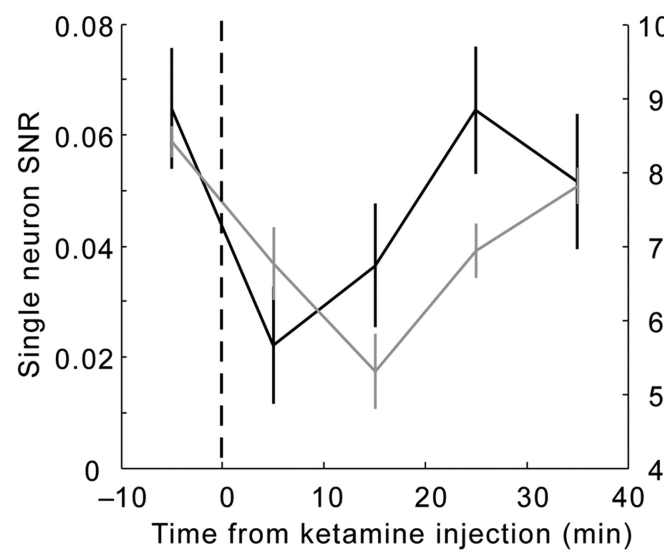

B

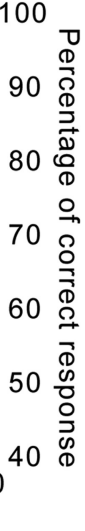

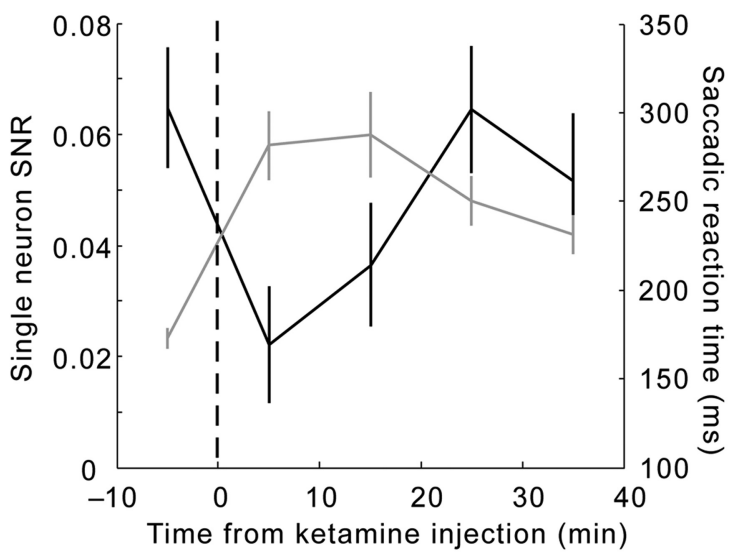

Figure 4. Similarity in the time course of changes in behavior and in single-unit SNR for task rules. $A$, The SNR at the single-unit level (black curve, left $y$-axis) dropped abruptly during the first 10 min after injection and recovered gradually. This time course mimics and slightly leads the course of change in the percentage of correct response from the animals (gray curve, right $y$-axis). $\boldsymbol{B}$, The time course of the SNR (black curve, left $y$-axis) mirrored the changes in saccadic reaction time (gray curve, right $y$-axis), especially during the preinjection period and the first 20 min after injection. Error bars indicate the SEM.

Therefore, ketamine enhanced trial-to-trial variance in both prosaccade and anti-saccade trials to the same extent, during delay periods preceding both correct and erroneous responses. Figure $3 \mathrm{H}$ shows the activity of a single neuron in both types of trials. The dashed lines delimit the delay periods. Whereas the neuron responded differently in the prosaccade (blue line) and the antisaccade (red line) trials before ketamine injection (Fig. $3 \mathrm{H}$, left), this distinction largely disappeared after the injection (Fig. $3 \mathrm{H}$, right). The loss of SNR for rules occurred despite the increase in overall activity.

To determine whether the change in SNR for rules tracked the timing in behavioral performance, we computed the SNR for each of the five $10 \mathrm{~min}$ periods (one before and four after the injection). Consistent with the findings above (Fig. 3B), ketamine significantly impaired the SNR within the first 20 min after injection (repeated-measures ANOVA, $F_{(4,1204)}=2.93, p=0.02$; Fig. $4 A$, black line, left $y$-axis). Both deterioration and rebound in the SNR appeared to slightly precede the decrease and subsequent recovery of correct responses (Fig. $4 A$, gray line, right $y$-axis). The course of change in the SNR (Fig. $4 B$, black line, left $y$-axis) also coincided with the increase and decrease in saccadic reaction time (Fig. $4 B$, gray line, right $y$-axis), although unlike the SNR, reaction time did not fully recover at the end of the sessions. Together with Figure 2, these results demonstrate that the SNR for rule representation was better correlated with behavioral changes than other measurements such as mean, SD, and CV of firing rates across trials.

\section{Effects of ketamine on the SNR for rule representation at ensemble level}

We then examined the effect of ketamine on the SNR at the ensemble level where interactions among neurons could be taken into consideration. We considered all simultaneously recorded neurons in a given session as part of an ensemble, without excluding any neuron on the basis of task selectivity. A single SNR was calculated for each ensemble, and the group statistics were performed across ensembles. The SNR for rule representation at the ensemble level had the same definition as at the single neuron level in that it was a ratio of the difference between prosaccade and antisaccade trials relative to the trial-to-trial variance. To calculate the ensemble rule signal, we summed the square of the differences in activity between prosaccade and anti-saccade trials from each neuron in the ensemble and took the square root of the sum. In other words, the signal was the Euclidean distance between the clouds of points in the MSUA space, which used the firing rates of each neuron in the ensemble as axes. To quantify and control for the generalized effect of ketamine, for each ensemble we computed the Euclidean distances in the MSUA space between shuffled groups of trials and subtracted them from the Euclidean distance between the prosaccade and antisaccade trials. The ensemble SNR also took the pooled covariance matrix rather than the pooled SD from both trial types as the denominator (i.e., the noise). The covariance matrix contained not only the trial-to-trial variance of each neuron but also the covariance between each neuronal pair in the ensemble. In all calculations, bootstrapping was used to control for the inequality in ensemble size and number of trials across sessions.

Because of the strong deleterious effect of ketamine on working memory performance, only six sessions had a sufficient number of correct trials of each trial type to analyze. We therefore had a small sample size for analysis, and each data point is overlaid on the bars as gray dots (Fig. 5A). When only correct trials were analyzed, ketamine did not change the overall ensemble SNR between prosaccade versus antisaccade trials (Wilcoxon signedrank test, $Z=1.57, p=0.12$; Fig. $5 A$ ). In contrast, ketamine changed the overall ensemble SNR between prosaccade versus antisaccade trials when error trials were included (paired $t$ test, $t_{(5)}=4.04, p=0.0037$; Fig. $5 B$ ). Overall, the effect of ketamine at the ensemble level closely resembled its effect in the individual neurons, as it disrupted the representation of rules during the delay periods even though its generalized effect on overall activity was controlled for.

The rule signal at the ensemble level was the backgroundcorrected Euclidean distance between points in the MSUA space associated with prosaccade versus antisaccade trials. If only correct trials were analyzed, this distance was not affected by ketamine $\left(t_{(5)}=-0.57, p=0.59\right.$; Fig. $\left.5 C\right)$. However, if both correct and error trials were considered, this distance was smaller after ketamine (paired $t$ test, $t_{(8)}=2.49, p=0.038$; Fig. $5 D$ ). These results are consistent with the findings from the single-unit analyses above and suggest that ketamine compromised the SNR for rule representation in the ensembles during the delay periods. 

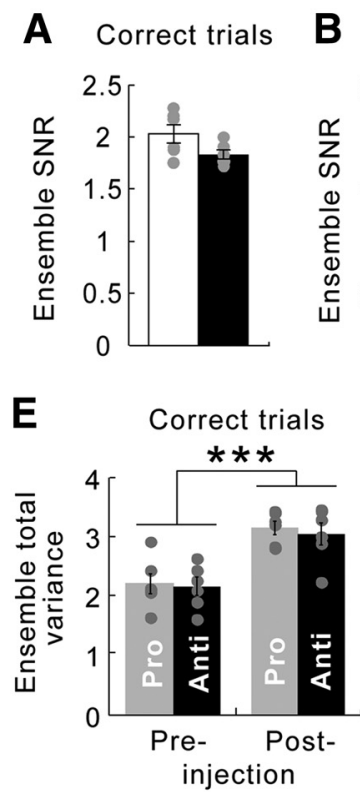
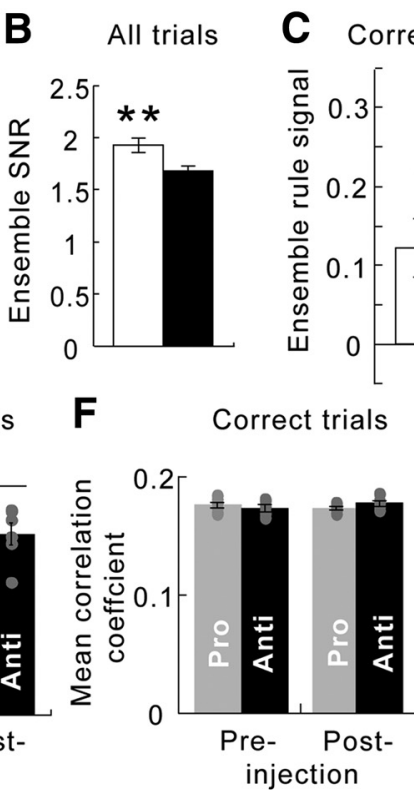
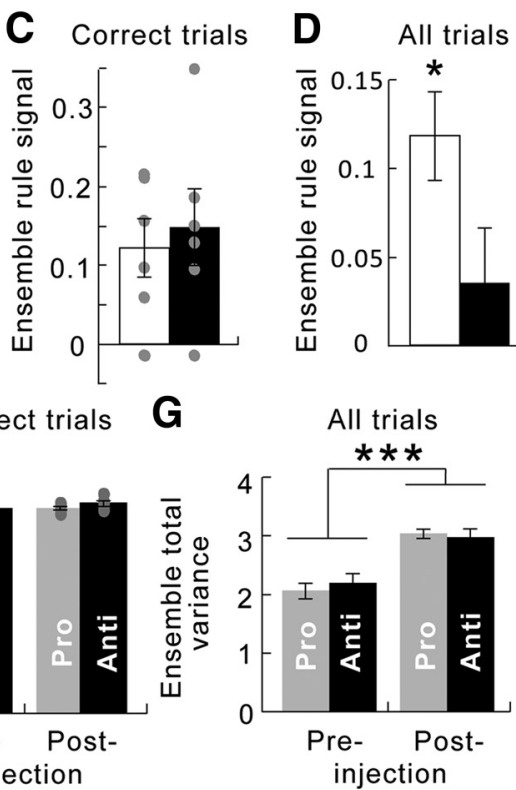

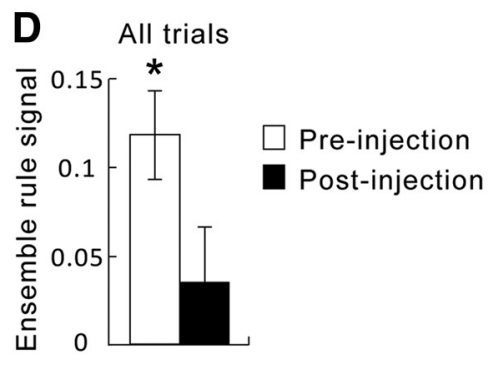

H All trials

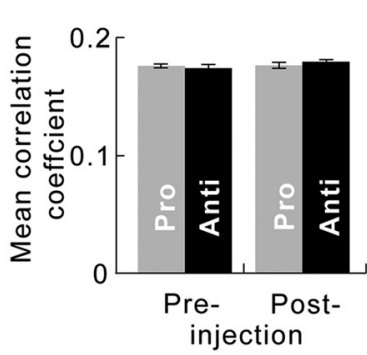

Figure 5. In whole ensembles, ketamine also weakened the SNR for rules via both a reduction in signal and an increase in noise. $\boldsymbol{A}$, Considering correct trials only, the SNR measured as the Mahalanobis distance $\left(D_{\text {Mah }}\right)$ between neural correlates of the two rules, remained unchanged by acute ketamine administration (white bar, before injection; black bar, after injection). Gray dots indicate values of individual data points. $\boldsymbol{B}$, When all trials were considered, the ensemble SNR was significantly compromised by ketamine administration. $\boldsymbol{C}$, Considering correct trials only, the rule signal, defined as the Euclidean distance $\left(D_{\text {Euc }}\right)$ between ensemble activities associated with the two rules, remained unchanged by ketamine. $\boldsymbol{D}$, When error trials were also included, however, the signal was weakened after ketamine injection. $\boldsymbol{E}$ and $\boldsymbol{F}$ consider correct trials only. $\boldsymbol{E}$, The total variance, part of the noise factored into the ensemble SNR calculation, was significantly enhanced by ketamine injection (left vs right bars) to the same extent in both task rules (gray vs black bars). $\boldsymbol{F}$, The averaged correlation coefficient, which is another contributing factor to ensemble SNR, was not changed by ketamine (left vs right bars) regardless of the task rule (gray vs black bars). $\boldsymbol{G}$ and $\boldsymbol{H}$ consider all trials, including errors. $\boldsymbol{G}$, The total variance was enhanced by ketamine injection (left vs right bars) to the same extent in both task rules (gray vs black bars). $\boldsymbol{H}$, The averaged correlation coefficient remained unchanged after ketamine administration (left vs right bars) in both prosaccade and antisaccade trials (gray vs black bars). ${ }^{*} p<0.05,{ }^{* *} p<0.005,{ }^{* * *} p<0.0001$.

The noise component of the ensemble SNR had two aspects, the variance in each neuron's activities and the covariance between the activities of each pair of neurons, which were assessed by their correlation coefficient in addition to their variance. When only correct trials were considered, ketamine injection resulted in a significant increase in the trial-to-trial single neuron variance for both prosaccade and antisaccade trials (repeatedmeasures ANOVA; main effect of treatment, $F_{(1,10)}=40.3, p=$ $8.4 \times 10^{-5}$; no effect of rule, $F_{(1,10)}=0.041, p=0.84$; Fig. $5 E$ ). Yet ketamine caused no change in the averaged absolute pairwise correlation coefficient (repeated-measures ANOVA, $F_{(1,10)}=$ $0.34, p=0.57$; Fig. $5 F$ ). These results were similar even when error trials were added as the total trial-to-trial variance of each neuron was increased for both prosaccade and antisaccade trials (repeated-measures ANOVA, $F_{(1,16)}=49.1, p=3.0 \times 10^{-6}$; no effect of rule, $F_{(1,10)}=0.0091, p=0.93$; Fig. $\left.5 G\right)$, and the correlation coefficients between neurons was unaffected (repeatedmeasures ANOVA, $F_{(1,16)}=1.48, p=0.24$; Fig. $5 H$ ). Therefore, whereas ketamine increased the trial-to-trial variance in ensemble activity, it did not affect the correlations between neurons across trials. In summary, a decrease in signal strength as well as an increase in noise both contributed to the reduction in the SNR for rules in the LPFC ensembles.

As a single-session example, the ensemble activity in each trial was collapsed to a two-dimensional plane using MDS (Fig. 6A). Although the MDS was performed using both preinjection and postinjection trials combined, they were plotted separately for clarity (Fig. 6A,C). Each dot represents the two-dimensional projection of the $61 \times 1$ population vector (one firing rate value for each neuron) recorded during the delay period of a single trial. Dots were colored blue if they were activities associated with prosaccade trials and red if they were from antisaccade trials.
Comparing Figure 6, $A$ and $C$, it was clear that the population activities from each type of trial were better clustered and differentiated from the other trial type before versus after the injection. This meant that compared with the preinjection period, ketamine increased the noise in the ensemble activity pattern across trials for a given rule, which in turn produced a lower rule-based SNR. In addition, Figure 6 also shows the averaged standardized activity from each neuron in the 61-unit ensemble before (Fig. $6 B$ ) and after (Fig. 6D) the ketamine injection. Whereas ketamine caused more neurons to fire above their mean activity level (Fig. 6D) compared with baseline (Fig. 6B), the signal, or the difference in the neurons' responses to the two rules, diminished (Fig. $6 B$, gray boxes). Together, delay-period activities from this ensemble provided an example of how both increased noise and weakened signal can affect the SNR for rules.

\section{Effects of ketamine on SNR for rule representation in different neuronal types}

Different types of neurons play different roles in the local cortical circuitry and may be differentially affected by ketamine on this task. We categorized the population into putative pyramidal neurons and putative fast-spiking interneurons based on the bimodal distribution of their peak-valley latencies (Fig. 7A; Johnston et al., 2009). Neurons with peak-valley latencies $>270 \mu$ s were classified as BSNs, whereas those with peak-valley latencies smaller than $270 \mu$ s were NSNs. BSNs, or putative pyramidal neurons, consisted of $\sim 84 \%$ of all neurons, whereas NSNs, or putative fast-spiking interneurons, consisted of $\sim 16 \%$ of the population. When all trials and both trial types were combined, the firing rates of the NSNs were higher than the BSNs (repeated-measures ANOVA, effect of neuronal type: $F_{(1,305)}=4.92, p=0.027$; Fig. $7 B)$. The NSNs also had greater trial-to-trial variance in their 
A

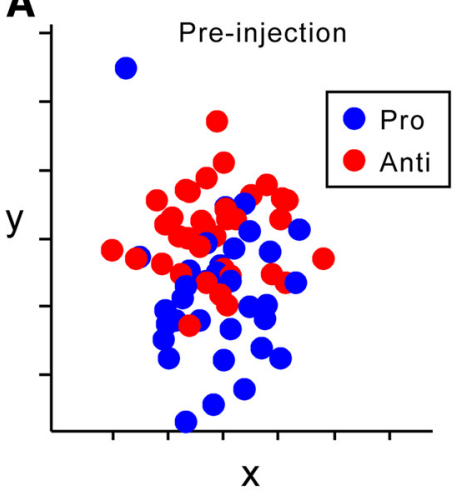

C

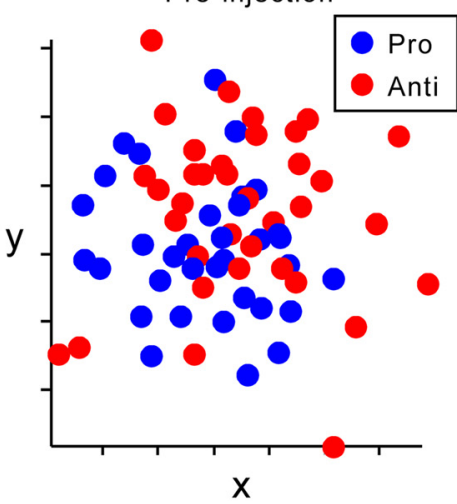

B

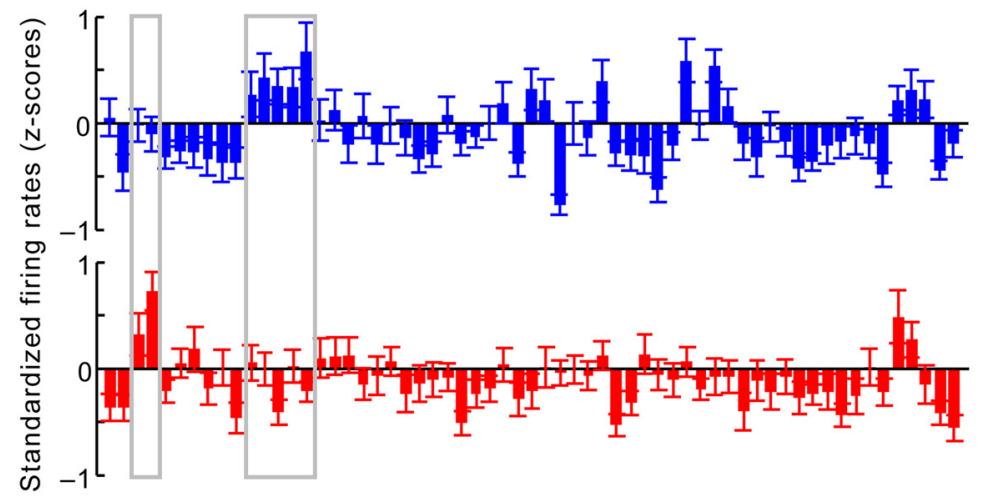

D

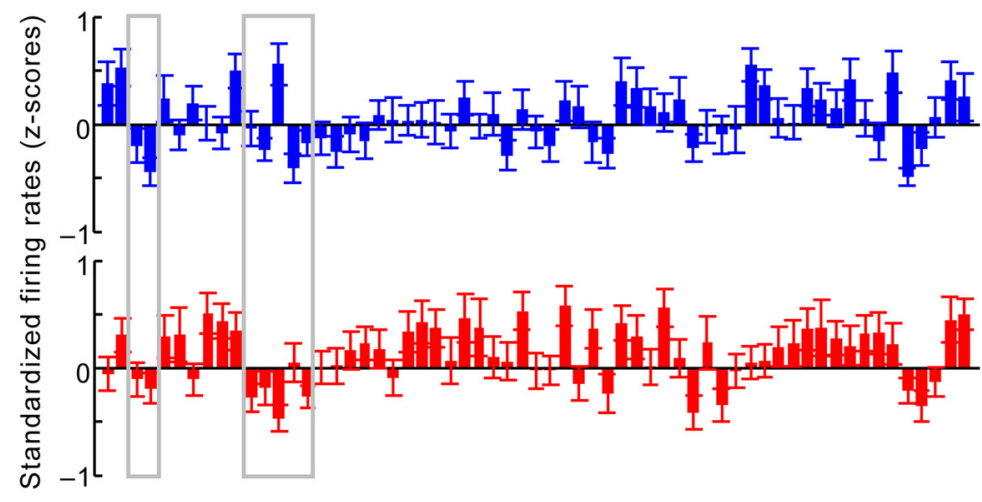

Figure 6. The effects of ketamine on signal and noise, visualized in a single ensemble. $A$, An example of a dimension-reduced MSUA space constructed from the standardized firing rates of 61 dorsolateral PFCneurons recorded during a single session, before ketamine injection. Each dot reflects the activities of all 61 neurons in the delay period of a single trial. Trials with the same rule (blue, prosaccade rule; red, antisaccade rule) are associated with similar ensemble activities, reflected as a relatively compact cluster that is distinct from the other cluster. $\boldsymbol{B}$, Averaged activities from each neuron in prosaccade (blue) and antisaccade (red) trials (in $z$-scores) before injection. Each bar represents the mean and SEM of activities from a single neuron. Gray boxes highlight neurons showing great difference in their responses to the two rules. $\boldsymbol{C}$, The MSUA space for the same ensemble after ketamine injection, dimension reduced together with activities shown in $\boldsymbol{A}$. Ketamine administration increased noise, or greater variance in ensemble activity across trials associated with the same rule, which is reflected as greater dispersion among dots of the same color. $\boldsymbol{D}$, Averaged activities from each neuron in prosaccade (blue) and antisaccade (red) trials (in z-scores) after ketamine injection. The same neurons highlighted in $\boldsymbol{A}$ (gray boxes) now show reduced difference in their responses to the two rules. Hence, in these neurons, ketamine resulted in a reduction in the signal strength for task rules.

activities (repeated-measures ANOVA, effect of neuronal type: $F_{(1,305)}=6.98, p=0.0087$; Fig. $\left.7 C\right)$. In each type of neuron, ketamine significantly increased both firing rates $(\mathrm{BSN}, p=7.7 \times$ $10^{-6}$; NSN, $p=5.4 \times 10^{-5}$; Fig. $\left.7 B\right)$ and trial-to-trial variance (BSN, $p=7.7 \times 10^{-6}$; NSN, $p=8.4 \times 10^{-6}$; Fig. $7 C$ ).

To study the SNR in different types of neurons, we repeated the analyses for both the BSNs and the NSNs separately. When considering all trials, ketamine had a main effect on SNR for rules (repeated-measures ANOVA, effect of drug: $F_{(1,305)}=5.15, p=$ 0.024; Fig. $7 D)$, with a marginal effect of neuron type $\left(F_{(1,305)}=\right.$ $3.10, p=0.079)$. Whereas ketamine impaired the SNR in the BSNs (Tukey's post hoc test, $p=0.038$ ), this effect was not significant in the NSNs $(p=0.56)$. When only the delay periods before correct responses were considered, there were no effects of drug or neuron type (repeated-measures ANOVA; drug injection, $F_{(1,305)}=0.12, p=0.73$; neuron type, $F_{(1,305)}=1.48, p=0.23$; Fig. 7E).

\section{Discussion}

Working memory is a process supported by neurons of various types organized into intricate microcircuits, which promote and sustain signal in a noisy background (Compte et al., 2000; Durstewitz et al., 2000b; Murray et al., 2014). Using a task that required the monkeys to represent one of the two saccade rules in working memory, we analyzed the effects of NMDA receptor blockade in the LPFC on the signal and noise in rule representation, which incorporates both the strength and the consistency in information representation. We found that both weakening of the signal and the amplification of the noise across trials contributed to the ketamine-induced deterioration in the SNR. This was the case both within individual neurons and at the ensemble level. Although ketamine affected the mean, SD, and coefficient of variation of delay-period firing rates across trials, unlike the SNR, none of these statistics followed a time course similar to changes in behavioral performance. The weakening of the rule signal, which was defined as the background-corrected difference between the mean firing rates during the two trial types, was quite remarkable given the overall increase in LPFC activity.

Numerous studies have thoroughly examined the differentiation of spatial locations in working memory by LPFC neurons (Funahashi et al., 1989; Rao et al., 1999, 2000; Compte et al., 2000; Constantinidis et al., 2001; Zhou et al., 2012). Whereas the average response of LPFC neurons suggests they strongly represent information during delays, the consistency in these representations has been mostly ignored as a critical task-relevant variable. Here, we used the SNR to capture both the strength and the trial-to-trial consistency in rule representation by LPFC neurons. 
The weakening in the SNR after ketamine injection was partially explained by the increase in the trial-to-trial variance in the firing rates of LPFC neurons, which was common to both types of neurons. Because the increase in variance was not rule specific, we speculate that it may directly contribute to the longer reaction time in all trials performed after ketamine injections (Skoblenick and Everling, 2014). It may also contribute to the greater probability of committing an error.

Ketamine may enhance cortical activity by increasing glutamate release, which boosts AMPA/kainate receptor currents (Moghaddam et al., 1997; Wang et al., 2013; Moran et al., 2015). This increase in glutamatergic transmission in turn may reflect a disinhibition effect on excitatory neurons, as a result of a stronger effect of ketamine on the NMDA receptors of local parvalbumin-positive GABAergic interneurons (Behrens et al., 2007; McNally et al., 2011). Consistent with this hypothesis, NMDA blockade via MK-801 has been reported to result in increased and decreased firing rates in BSNs and NSNs, respectively, in the rat medial $\mathrm{PFC}$ (Homayoun and Moghaddam, 2007). By contrast, we found that ketamine enhanced activity in the NSNs. The discrepancy could be attributable to species differences or because different compounds were used. The effect of ketamine on LPFC neurons may have its origins within the LPFC itself or may be a secondary effect of changes in the firing of neurons in afferent regions. In support of this latter possibility, acute ketamine administration has been reported to cause hyperconnectivity between the PFC and other cortical and thalamic regions (Dawson et al., 2013, 2014; Anticevic et al., 2015b). Such hyperconnectivity was also observed in patients with early-stage schizophrenia (Anticevic et al., 2015a,b).

Despite the increase in overall activity, the rule signal was weakened by ketamine during the delay periods preceding error responses. This may be a direct result of NMDA receptor blockade, which was shown to be critical for the persistent firing during the delay periods in spatial working memory tasks (Compte et al., 2000; Wang et al., 2013).

Consistent with previous studies (Skoblenick and Everling, 2012, 2014; Wang et al., 2013), we found that the strength of the rule representation during the delay periods of postinjection correct trials was similar before and after the injection. Ketamine at the dosage used may have spared enough NMDA receptors to support the representation of a single rule but not the differentiation of multiple rules. Alternatively, the representation of a single rule could be maintained by AMPA receptor currents, as long as the process engages a sufficiently great number of neurons firing with weak synchrony (Gutkin et al., 2001; Hansel and Mato, 2001; Koulakov, 2001; Latham and Nirenberg, 2004).

Although the SNR appears to have construct validity in characterizing rule representation, its face validity depends on whether it parallels the time course of changes in behavior. Only

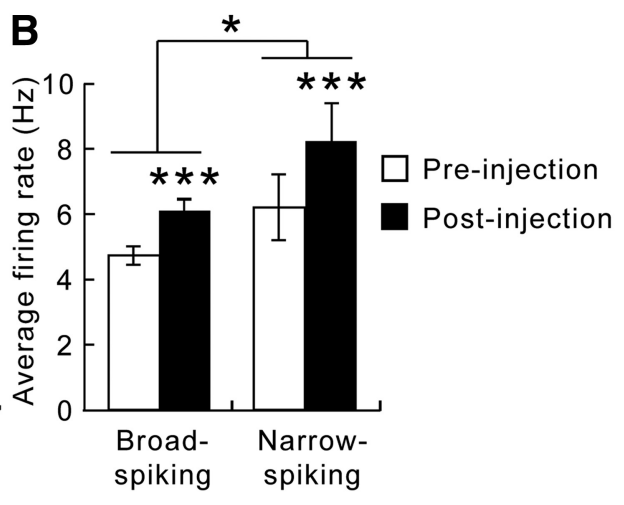

E
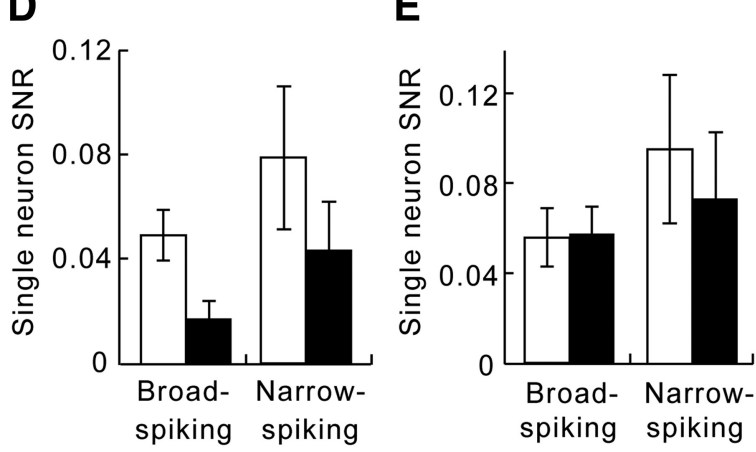

spiking spiking

Figure 7. Ketamine exerted similar effects on the activities of different types of neurons. $\boldsymbol{A}$, Neurons were classified into two the BSNs (left bars) both types of neurons showed an increase in activity level after ketamine injection (open vs filled bars). (in $\boldsymbol{E}$, On correct trials only, the SNR did not change after ketamine injection (empty vs filled bars), nor did it differ between neuron types (left vs right bars). Error bars indicate the SEM. ${ }^{*} p<0.05,{ }^{* *} p<0.005,{ }^{* * *} p<0.0001$.

ketamine induced the change in the SNR and not the enhancement in firing or change in the CV and paralleled the temporal profile of the change in task performance. This distinction highlights the strong behavioral and cognitive relevance of the difference between activities associated with the two rules and the confounding effect of overall increase in activity that was not specific to rule representation. Interestingly, recent studies have linked the increase in overall activity to the antidepressant effect of ketamine (Duman and Aghajanian, 2012; Fuchikami et al., 2015; Liu et al., 2015). Therefore, ketamine-induced working memory impairment and its antidepressant/anxiolytic effects may involve distinct cellular and synaptic processes.

Our findings have important implications for the discovery of effective pharmacological treatments for schizophrenia. Because NMDA receptor hypofunction leads to excessive cortical excitation (Moghaddam et al., 1997; Jackson et al., 2004), agonists for the group II metabotropic glutamate receptors (mGluR2/3), which reduce glutamate release, have received much attention for their potential therapeutic effect in schizophrenia (Moghaddam and Krystal, 2012). Initially, mGluR2/3 agonists were found to be effective in alleviating symptoms, including working memory deficits, in both animal models (Moghaddam and Adams, 1998) and human patients (Krystal et al., 2005; Patil et al., 2007). However, a more recent clinical trial failed to demonstrate efficacy for the mGluR2/3 agonist LY2140023 (Downing et al., 2014). To better alleviate working memory impairment, we speculate that a combined inhibition of glutamate release and facilitation of 
NMDA receptor function (D'Souza et al., 2012) may be necessary to restore both the strength and the consistency in working memory representation in the LPFC.

\section{References}

Anticevic A, Hu X, Xiao Y, Hu J, Li F, Bi F, Cole MW, Savic A, Yang GJ, Repovs G, Murray JD, Wang XJ, Huang X, Lui S, Krystal JH, Gong Q (2015b) Early-course unmedicated schizophrenia patients exhibit elevated prefrontal connectivity associated with longitudinal change. J Neurosci 35: 267-286. CrossRef Medline

Anticevic A, Corlett PR, Cole MW, Savic A, Gancsos M, Tang Y, Repovs G, Murray JD, Driesen NR, Morgan PT, Xu K, Wang F, Krystal JH (2015a) $\mathrm{N}$-methyl-D-aspartate receptor antagonist effects on prefrontal cortical connectivity better model early than chronic schizophrenia. Biol Psychiatry 77:569-580. CrossRef Medline

Baddeley A, Della Sala S (1996) Working memory and executive control. Philos Trans R Soc Lond B Biol Sci 351:1397-1403; discussion 1403-1404. Medline

Behrens MM, Ali SS, Dao DN, Lucero J, Shekhtman G, Quick KL, Dugan LL (2007) Ketamine-induced loss of phenotype of fast-spiking interneurons is mediated by NADPH-oxidase. Science 318:1645-1647. CrossRef Medline

Blackman RK, Macdonald AW 3rd, Chafee MV (2013) Effects of ketamine on context-processing performance in monkeys: a new animal model of cognitive deficits in schizophrenia. Neuropsychopharmacology 38:20902100. CrossRef Medline

Compte A, Brunel N, Goldman-Rakic PS, Wang XJ (2000) Synaptic mechanisms and network dynamics underlying spatial working memory in a cortical network model. Cereb Cortex 10:910-923. CrossRef Medline

Condy C, Wattiez N, Rivaud-Péchoux S, Gaymard B (2005) Ketamineinduced distractibility: an oculomotor study in monkeys. Biol Psychiatry 57:366-372. CrossRef Medline

Constantinidis C, Wang XJ (2004) A neural circuit basis for spatial working memory. Neuroscientist 10:553-565. CrossRef Medline

Constantinidis C, Franowicz MN, Goldman-Rakic PS (2001) Coding specificity in cortical microcircuits: a multiple-electrode analysis of primate prefrontal cortex. J Neurosci 21:3646-3655. Medline

Coyle JT (2006) Glutamate and schizophrenia: beyond the dopamine hypothesis. Cell Mol Neurobiol 26:365-384. Medline

Dawson N, Morris BJ, Pratt JA (2013) Subanaesthetic ketamine treatment alters prefrontal cortex connectivity with thalamus and ascending subcortical systems. Schizophr Bull 39:366-377. CrossRef Medline

Dawson N, McDonald M, Higham DJ, Morris BJ, Pratt JA (2014) Subanesthetic ketamine treatment promotes abnormal interactions between neural subsystems and alters the properties of functional brain networks. Neuropsychopharmacology 39:1786-1798. CrossRef Medline

Downing AM, Kinon BJ, Millen BA, Zhang L, Liu L, Morozova MA, Brenner R, Rayle T, Nisenbaum L, Zhao F, Gomez J (2014) A double-bind, placebo-controlled comparator study of LY2140023 monohydrate in patients with schizophrenia. BMC Psychiatry 14:351. CrossRef Medline

D'Souza DC, Singh N, Elander J, Carbuto M, Pittman B, Udo de Haes J, Sjogren M, Peeters P, Ranganathan M, Schipper J (2012) Glycine transporter inhibitor attenuates the psychotomimetic effects of ketamine in healthy males: preliminary evidence. Neuropsychopharmacology 37: 1036-1046. CrossRef Medline

Duman RS, Aghajanian GK (2012) Synaptic dysfunction in depression: potential therapeutic targets. Science 338:68-72. CrossRef Medline

Durstewitz D (2004) Neural representation of interval time. Neuroreport 15:745-749. CrossRef Medline

Durstewitz D, Seamans JK, Sejnowski TJ (2000a) Dopamine-mediated stabilization of delay-period activity in a network model of prefrontal cortex. J Neurophysiol 83:1733-1750. Medline

Durstewitz D, Seamans JK, Sejnowski TJ (2000b) Neurocomputational models of working memory. Nat Neurosci [Suppl] 3:1184-1191. CrossRef Medline

Durstewitz D, Vittoz NM, Floresco SB, Seamans JK (2010) Abrupt transitions between prefrontal neural ensemble states accompany behavioral transitions during rule learning. Neuron 66:438-448. CrossRef Medline

Elvevåg B, Goldberg TE (2000) Cognitive impairment in schizophrenia is the core of the disorder. Crit Rev Neurobiol 14:1-21. Medline

Enomoto T, Floresco SB (2009) Disruptions in spatial working memory, but not short-term memory, induced by repeated ketamine exposure. Prog Neuropsychopharmacol Biol Psychiatry 33:668-675. CrossRef Medline
Fuchikami M, Thomas A, Liu R, Wohleb ES, Land BB, DiLeone RJ, Aghajanian GK, Duman RS (2015) Optogenetic stimulation of infralimbic PFC reproduces ketamine's rapid and sustained antidepressant actions. Proc Natl Acad Sci U S A 112:8106-8111. CrossRef Medline

Funahashi S, Bruce CJ, Goldman-Rakic PS (1989) Mnemonic coding of visual space in the monkey's dorsolateral prefrontal cortex. J Neurophysiol 61:331-349. Medline

Fuster JM, Alexander GE (1971) Neuron activity related to short-term memory. Science 173:652-654. CrossRef Medline

Gil-da-Costa R, Stoner GR, Fung R, Albright TD (2013) Nonhuman primate model of schizophrenia using a noninvasive EEG method. Proc Nat Acad Sci U S A 110:15425-15430. CrossRef Medline

Goldman-Rakic PS, Castner SA, Svensson TH, Siever LJ, Williams GV (2004) Targeting the dopamine D1 receptor in schizophrenia: insights for cognitive dysfunction. Psychopharmacology (Berl) 174:3-16. Medline

Gutkin BS, Laing CR, Colby CL, Chow CC, Ermentrout GB (2001) Turning on and off with excitation: the role of spike-timing asynchrony and synchrony in sustained neural activity. J Comput Neurosci 11:121-134. CrossRef Medline

Hansel D, Mato G (2001) Existence and stability of persistent states in large neuronal networks. Phys Rev Lett 86:4175-4178. CrossRef Medline

Homayoun H, Moghaddam B (2007) NMDA receptor hypofunction produces opposite effects on prefrontal cortex interneurons and pyramidal neurons. J Neurosci 27:11496-11500. CrossRef Medline

Hyman JM, Ma L, Balaguer-Ballester E, Durstewitz D, Seamans JK (2012) Contextual encoding by ensembles of medial prefrontal cortex neurons. Proc Natl Acad Sci U S A 109:5086-5091. CrossRef Medline

Jackson ME, Homayoun H, Moghaddam B (2004) NMDA receptor hypofunction produces concomitant firing rate potentiation and burst activity reduction in the prefrontal cortex. Proc Natl Acad Sci U S A 101:84678472. CrossRef Medline

Johnston K, Everling S (2006) Neural activity in monkey prefrontal cortex is modulated by task context and behavioral instruction during delayedmatch-to-sample and conditional prosaccade-antisaccade tasks. J Cogn Neurosci 18:749-765. CrossRef Medline

Johnston K, DeSouza JF, Everling S (2009) Monkey prefrontal cortical pyramidal and putative interneurons exhibit differential patterns of activity between prosaccade and antisaccade tasks. J Neurosci 29:5516-5524. CrossRef Medline

Koulakov AA (2001) Properties of synaptic transmission and the global stability of delayed activity states. Network 12:47-74. CrossRef Medline

Krystal JH, Abi-Saab W, Perry E, D'Souza DC, Liu N, Gueorguieva R, McDougall L, Hunsberger T, Belger A, Levine L, Breier A (2005) Preliminary evidence of attenuation of the disruptive effects of the NMDA glutamate receptor antagonist, ketamine, on working memory by pretreatment with the group II metabotropic glutamate receptor agonist, LY354740, in healthy human subjects. Psychopharmacology (Berl) 179: 303-309. CrossRef Medline

Latham PE, Nirenberg S (2004) Computing and stability in cortical networks. Neural Comput 16:1385-1412. CrossRef Medline

Lett TA, Voineskos AN, Kennedy JL, Levine B, Daskalakis ZJ (2014) Treating working memory deficits in schizophrenia: a review of the neurobiology. Biol Psychiatry 75:361-370. CrossRef Medline

Liu RJ, Ota KT, Dutheil S, Duman RS, Aghajanian GK (2015) Ketamine strengthens CRF-activated amygdala inputs to basal dendrites in mPFC layer $\mathrm{V}$ pyramidal cells in the prelimbic but not infralimbic subregion, a key suppressor of stress responses. Neuropsychopharmacology 40:20662075. CrossRef Medline

Lorrain DS, Baccei CS, Bristow LJ, Anderson JJ, Varney MA (2003) Effects of ketamine and $\mathrm{N}$-methyl-D-aspartate on glutamate and dopamine release in the rat prefrontal cortex: modulation by a group II selective metabotropic glutamate receptor agonist LY379268. Neuroscience 117: 697-706. CrossRef Medline

McNally JM, McCarley RW, McKenna JT, Yanagawa Y, Brown RE (2011) Complex receptor mediation of acute ketamine application on in vitro gamma oscillations in mouse prefrontal cortex: modeling gamma band oscillation abnormalities in schizophrenia. Neuroscience 199:51-63. CrossRef Medline

Moghaddam B, Adams BW (1998) Reversal of phencyclidine effects by a group II metabotropic glutamate receptor agonist in rats. Science 281: 1349-1352. CrossRef Medline

Moghaddam B, Krystal JH (2012) Capturing the angel in "angel dust": 
twenty years of translational neuroscience studies of NMDA receptor antagonists in animals and humans. Schizophr Bull 38:942-949. CrossRef Medline

Moghaddam B, Adams B, Verma A, Daly D (1997) Activation of glutamatergic neurotransmission by ketamine: a novel step in the pathway from NMDA receptor blockade to dopaminergic and cognitive disruptions associated with the prefrontal cortex. J Neurosci 17:2921-2927. Medline

Moran RJ, Jones MW, Blockeel AJ, Adams RA, Stephan KE, Friston KJ (2015) Losing control under ketamine: suppressed cortico-hippocampal drive following acute ketamine in rats. Neuropsychopharmacology 40: 268-277. CrossRef Medline

Murray JD, Anticevic A, Gancsos M, Ichinose M, Corlett PR, Krystal JH, Wang XJ (2014) Linking microcircuit dysfunction to cognitive impairment: effects of disinhibition associated with schizophrenia in a cortical working memory model. Cereb Cortex 24:859-872. CrossRef Medline

Olney JW, Farber NB (1997) Discussion of Bogerts' temporolimbic system theory of paranoid schizophrenia. Schizophr Bull 23:533-536. CrossRef Medline

Patil ST, Zhang L, Martenyi F, Lowe SL, Jackson KA, Andreev BV, Avedisova AS, Bardenstein LM, Gurovich IY, Morozova MA, Mosolov SN, Neznanov NG, Reznik AM, Smulevich AB, Tochilov VA, Johnson BG, Monn JA, Schoepp DD (2007) Activation of mGlu2/3 receptors as a new approach to treat schizophrenia: a randomized Phase 2 clinical trial. Nat Med 13:1102-1107. CrossRef Medline

Quintana J, Fuster JM (1999) From perception to action: temporal integrative functions of prefrontal and parietal neurons. Cereb Cortex 9:213221. CrossRef Medline

Rao SG, Williams GV, Goldman-Rakic PS (1999) Isodirectional tuning of adjacent interneurons and pyramidal cells during working memory: evidence for microcolumnar organization in PFC. J Neurophysiol 81:19031916. Medline

Rao SG, Williams GV, Goldman-Rakic PS (2000) Destruction and creation of spatial tuning by disinhibition: $\mathrm{GABA}_{\mathrm{A}}$ blockade of prefrontal cortical neurons engaged by working memory. J Neurosci 20:485-494. Medline

Rushforth SL, Steckler T, Shoaib M (2011) Nicotine improves working memory span capacity in rats following sub-chronic ketamine exposure. Neuropsychopharmacology 36:2774-2781. CrossRef Medline
Seamans JK, Nogueira L, Lavin A (2003) Synaptic basis of persistent activity in prefrontal cortex in vivo and in organotypic cultures. Cereb Cortex 13:1242-1250. CrossRef Medline

Shen K, Kalwarowsky S, Clarence W, Brunamonti E, Pare M (2010) Beneficial effects of the NMDA antagonist ketamine on decision processes in visual search. J Neurosci 30:9947-9953. CrossRef Medline

Skoblenick K, Everling S (2012) NMDA antagonist ketamine reduces task selectivity in macaque dorsolateral prefrontal neurons and impairs performance of randomly interleaved prosaccades and antisaccades. J Neurosci 32:12018-12027. CrossRef Medline

Skoblenick K, Everling S (2014) N-methyl-d-aspartate receptor antagonist ketamine impairs action-monitoring activity in the prefrontal cortex. J Cogn Neurosci 26:577-592. CrossRef Medline

Spruston N, Jonas P, Sakmann B (1995) Dendritic glutamate receptor channels in rat hippocampal CA3 and CA1 pyramidal neurons. J Physiol 482: 325-352. CrossRef Medline

Stoet G, Snyder LH (2006) Effects of the NMDA antagonist ketamine on taskswitching performance: evidence for specific impairments of executive control. Neuropsychopharmacology 31:1675-1681. CrossRef Medline

van Os J, Kapur S (2009) Schizophrenia. Lancet 374:635-645. CrossRef Medline

Wang M, Yang Y, Wang CJ, Gamo NJ, Jin LE, Mazer JA, Morrison JH, Wang XJ, Arnsten AF (2013) NMDA receptors subserve persistent neuronal firing during working memory in dorsolateral prefrontal cortex. Neuron 77:736-749. CrossRef Medline

Wang XJ (1999) Synaptic basis of cortical persistent activity: the importance of NMDA receptors to working memory. J Neurosci 19:9587-9603. Medline

Wesierska M, Macias-Gonzalez R, Bures J (1990) Differential effect of ketamine on the reference and working memory versions of the Morris water maze task. Behav Neurosci 104:74-83. CrossRef Medline

Zhou X, Katsuki F, Qi XL, Constantinidis C (2012) Neurons with inverted tuning during the delay periods of working memory tasks in the dorsal prefrontal and posterior parietal cortex. J Neurophysiol 108:31-38. CrossRef Medline 